\title{
Erratum to: Health-related quality of life in women with fibromyalgia: clinical and psychological factors associated
}

Ricardo Pereira Campos •

Maria Isabel Vázquez Rodríguez

Published online: 30 December 2011

(C) Clinical Rheumatology 2011

\section{Erratum to: Clin Rheumatol}

DOI 10.1007/s10067-011-1870-7

In the version of the article initially published, the name of the second author was incorrectly presented. Maria Isabel Vázquez Rodríguez name appears correctly above and below.

The online version of the original article can be found at http://dx.doi. org/10.1007/s10067-011-1870-7.

R. P. Campos $(\bowtie)$

ISJD-S. José's Health House,

Largo S. João de Deus, No. 1,

4755-044, Areias de Vilar, Barcelos, Portugal

e-mail: ricardo.campos@isjd.pt

M. I. Vázquez Rodríguez

Clinical Psychology and Psychobiology Department,

Psychology School, Santiago de Compostela's University,

Rúa Xosé María Suárez Núñez, s/n. Campus sur,

15782, Santiago de Compostela, Spain

e-mail: mariaisabel.vazquez@usc.es 